\title{
CAMBIOS AL ACUERDO DE PAZ CON LAS FARC-EP Y DERECHOS DE LAS VÍCTIMAS*
}

\section{Changes to the Peace Agreement with the FARC-EP and the Rights of victims}

Eduardo Matyas Camargo**

Corporación Universitaria Republicana. Bogotá D.C.

«El resarcimiento de las víctimas estará en el centro de cualquier acuerdo» ${ }^{1}$

Recepción: 13 de abril de 2017. Aceptación: 21 de mayo de 2017.

DOI: http://dx.doi.org/10.21017/Rev.Repub.2017.v22.a21

\section{RESUMEN}

La Justicia Especial de Paz es una componente del Sistema integral de Verdad, Justicia, Reparación y no Repetición. El sistema está conformado por tres mecanismos: la Jurisdicción Especial para la Paz (JEP), la Comisión de la verdad y la Unidad para la Búsqueda de Personas dadas por Desaparecidas. Los cambios a la JEP en el Acuerdo del Teatro Colón y a través del Acto Legislativo número 1 del 4 de abril de 2017 que desarrolla el punto 5 del Acuerdo y crea la JEP afectan la búsqueda de la verdad y la justicia respecto a los terceros partícipes en el conflicto y los agentes del Estado, al condicionar la responsabilidad de los primeros en los crímenes de carácter internacional solo cuando haya sido sistemático y la responsabilidad de los mandos militares a la existencia compleja de pruebas en relación con los delitos. El problema de investigación se presenta de la siguiente manera: ¿En qué medida el acto legislativo que crea la Justicia Especial de Paz

* Este artículo es producto de la investigación: Proceso de paz y justicia transicional, desarrollada dentro de la línea de investigación Derecho Penal y Política Criminal del Grupo de Investigación Derecho Público, perteneciente al Centro de Investigaciones de la Corporación Universitaria Republicana, reconocido por Colciencias.

** Abogado de la Universidad Autónoma de Bucaramanga, con Especialización en Derecho Constitucional en la Universidad Nacional de Colombia, Estudios de Maestría en filosofía del derecho e interpretación jurídica en la Universidad Libre. Docente investigador de la Corporación Universitaria Republicana. Profesor de Derecho Internacional Humanitario y DD.HH en la Maestría de la Universidad Pedagógica y Tecnológica de Colombia -UPTC. Correo electrónico: ematyasdih@hotmail.com

1 Acuerdo final para la terminación del conflicto y la construcción de una paz estable y duradera. Introducción. En: Moreno Alfonso, Rene. Itinerario del proceso de paz en Colombia. Bogotá, Ediciones Nueva Jurídica, 2016, p. 35. 
mengua los derechos a la verdad, a la justicia y a la reparación de las víctimas? Con los cambios introducidos se debilitó los derechos de las víctimas respecto a los terceros involucrados en el conflicto y los agentes del Estado, y se impusieron mayores responsabilidades a los integrantes de las FARC para tener acceso a la amnistía, indulto y tratamientos especiales.

Palabras clave: Justicia Especial de Paz, acuerdos, víctimas, reparación, penas alternativas, tratamiento penal especial, restricción de la libertad, amnistía, indulto, guerrilla, agentes del Estado.

\begin{abstract}
The Special Peace Justice is a component of the Comprehensive System of Truth, Justice, Reparation and Non-Repetition. The system is made up of three mechanisms: the Special Jurisdiction for Peace (JEP), the truth commission and the Unit for the Search of Persons given by Missing Persons. The changes to the JEP in the Agreement of the Teatro Colón and through Legislative Act No. 1 of April 4, 2017 that develops point 5 of the Agreement and creates the JEP affects the search for truth and justice regarding third parties in Conflict and state agents, by making the former responsible for crimes of an international character only when it has been systematic and the responsibility of military commanders for the complex existence of evidence in relation to crimes. The research problem is presented as follows: to what extent does the legislative act creating the Special Peace Justice diminish the rights to truth, justice and reparation of victims? With the changes introduced, the rights of the victims with respect to the third parties involved in the conflict were weakened by the agents of the State and the members of the FARC were given greater responsibilities to have access to amnesty, pardon and special treatment.
\end{abstract}

Key word: Special Justice Peace, agreements, victims, reparations, alternative penalties, special criminal treatment, restriction of freedom, amnesty, pardon, guerrilla, agents of the State.

\title{
1. PROBLEMA DE INVESTIGACIÓN
}

El 4 de abril de 2017 fue promulgado el Acto Legislativo transitorio que crea el Sistema integral de Verdad, Justicia, Reparación y no Repetición, y como uno de sus componentes la Justicia Especial de Paz, que juzgará a integrantes de la fuerza pública, integrantes de la guerrilla de las FARC y terceros responsables de financiar y promover el conflicto armado y graves crímenes contra el Derecho Internacional Humanitario, crímenes de guerra y otros delitos que en forma sistemática han afectado a la población colombiana. 
Los Acuerdos Gobierno-FARC y la Justicia Especial de Paz establecen como eje el restablecimiento de los derechos de las víctimas, bajo del principio del reconocimiento de la verdad plena de lo ocurrido y la responsabilidad por parte de todos quienes participaron de manera directa o indirecta en el conflicto, que garantice la verdad, la justicia, la reparación y la no repetición.

Sin embargo, el texto de la JEP resulta polémico, porque las normas aprobadas establecen compromisos diferentes para los actores respecto al reconocimiento de la verdad y la responsabilidad de los mismos, tratamientos diferenciados respecto a los responsables de graves crímenes contra las víctimas y el resarcimiento de las víctimas, y previsiones que le permiten a criminales de graves delitos no relacionados con el conflicto armado acceder a tratamiento penal especial que conllevan un acceso espurio a la JEP, con la consiguiente impunidad en contravía de los propósito del Acuerdo de Paz.

La identificación y crítica de las previsiones normativas que van en contravía de los fines de la JEP constituye uno de los objetivos de la investigación sobre los acuerdos de paz y la justicia transicional, y contribuir con ello al conocimiento de esta normatividad transitoria, a una interpretación y práctica de la misma que no menoscabe los derechos de las víctimas, y la prevención y superación en lo posible en las normas que desarrollen el Acuerdo y el acto legislativo que establece la JEP. El problema de investigación se sintetiza en una pregunta problematizadora: ¿En qué medida el acto legislativo que crea la Justicia Especial de Paz mengua los derechos a la verdad, a la justicia y a la reparación de las víctimas?

\section{ESTRATEGIA METODOLÓGICA}

El proyecto de investigación sobre el Acuerdo Final comprende el estudio fragmentado de los diversos temas abordados en el documento ya refrendado por el legislativo e implementado a través de actos legislativos y leyes tramitadas por el procedimiento abreviado (fast track) y decretos reglamentarios facultados por el acto legislativo que reglamentó este procedimiento especial.

En el presente documento se realiza el análisis de las instituciones y derechos previstos en el Acto Legislativo número 1 de 2017 que crea la Justicia Especial de Paz, estudio cualitativo que busca establecer las características de las órganos de la justicia transicional, y si los derechos y prerrogativas de las víctimas y obligaciones de los victimarios satisfacen las expectativas con que se ha establecido en el Acuerdo de paz. 
El método utilizado es esencialmente analítico de las instituciones y derechos establecidos a favor de las víctimas, y los procedimientos determinados y la identificación y restablecimiento de los derechos fundamentales afectados, competencias, universo y obligaciones de los destinatarios respecto a las víctimas.

\section{RESULTADOS DE LA INVESTIGACIÓN}

\subsection{Introducción}

Luego de cuatro años de negociaciones Gobierno-FARC, se alcanzó el 26 de septiembre de 2016 un Acuerdo final redactado en un complejo documento de 334 páginas $^{2}$. Acuerdo que luego fue elevado a norma jurídica través del Acto legislativo número 1 de 2017, que le introdujo numerosas y sustanciales modificaciones, hasta quedar transformado en los acuerdos del «fast track»; pues a pesar de lo firmado y de haberse previsto en el numeral 6.1.8 como un Acuerdo especial de conformidad con lo previsto en el artículo 3, Común de las Convenciones de Ginebra ${ }^{3}$, viene siendo modificado por el Congreso no solo a través de la aprobación del «Acuerdo Final», sino a través de los actos legislativos, leyes y decretos-ley que buscan implementar lo acordado.

Solo en la medida en que se vayan aprobando las diferentes normas jurídicas que implementan el Acuerdo se podrá ir conociendo con precisión los términos y alcances normativos exactos de los Acuerdos, los cuales pueden sufrir incluso modificaciones posteriores a través de leyes reglamentarias y ordinarias, aclaraciones y precisiones a través de decretos, o incluso derogaciones o precisiones por la Corte Constitucional a través de sentencias de constitucionalidad.

Hasta entonces se podrá precisar y profundizar en qué quedan jurídicamente los derechos de las víctimas a la verdad, a la justicia, a la reparación y las garantías de no repetición; qué significan o qué contenido tienen esas acepciones, cómo se implementarán, en qué tiempo, con quiénes, y si a la JEP y demás instituciones que se implementarán, como la Comisión para el esclarecimiento de la verdad, la convivencia y la no repetición y la Unidad de búsqueda de personas dadas por desaparecidas; y si concurrirán todos los actores

2 Acuerdo final para la terminación del conflicto y la construcción de una paz estable y duradera. Fuerzas Armadas Revolucionarias de Colombia, Bogotá 2016, 334 p.

3 Ibíd., p 231. 
del conflicto (victimarios), todas las víctimas, en qué términos y a través de qué mecanismos se les escuchará y se les reparará en una forma integral.

En razón a que aún no se ha terminado la implementación jurídica de los «Acuerdos», en este documento se precisan los cambios que se introdujeron en el Acuerdo final del Teatro Colón respecto a su antecesor el de La Habana-Cartagena, en cuanto a la Justicia Especial de Paz.

La sentencia de la Corte Constitucional del 17 de mayo de 2017, que declara inexequibilidad de los literales «h»y «j» del artículo 1 del Acto Legislativo 01 de 2016 que establece el fast track en los trámites de la legislación que desarrolla el Acuerdo de Paz con las FARC, literales que consagraban que las leyes y actos legislativos se votaran en bloque y sin introducir modificaciones a lo Acordado, pone en peligro el desarrollo legislativo de los Acuerdos del Teatro Colón, y potencialmente los derechos de las víctimas establecidos en lo pactado.

La Corte consideró que «en la medida en que tales disposiciones contenían limitaciones desproporcionadas a la capacidad deliberativa y decisoria del Congreso de la República en materias que pueden conducir a reformas estructurales del ordenamiento jurídico, sea en el nivel legal, o, incluso, en el constitucional, las mismas resultaban incompatibles con el principio democrático y de separación de poderes, y por consiguiente, sustituían parcialmente la Constitución». ${ }^{4}$

La Corte Constitucional expulsa del orden jurídico la condición que había puesto la norma acusada en la que se establecía que "los proyectos de ley y de Acto Legislativo solo podrán tener modificaciones siempre que se ajusten al contenido del Acuerdo Final» y que contarán con el aval previo del Gobierno Nacional. Lo mismo decidió respecto al numeral de la reforma que señalaba que «en la comisión y en las plenarias se decidirá sobre la totalidad de cada proyecto, con las modificaciones avaladas por el Gobierno Nacional, en una sola votación ${ }^{5}$. Ambos puntos eran considerados parte del corazón del mecanismo del fast track, que al ser declarados inexequibles debilita el cumplimiento de lo pactado que debía debatirse y aprobarse en bloque para evitar cambios sustanciales.

4 COLOMBIA. CORTE CONSTITUCIONAL. Comunicado No. 28 del 17 de mayo de 2017. Disponible en: http://www.corteconstitucional.gov.co/comunicados/No.\%2028\%20 comunicado\%2017\%20de\%20mayo \%20de\%202017.pdf. Consultada el 19 de mayo de 2017

5 ibíd. 


\subsection{Viacrucis jurídico de la justicia especial de paz (JEP)}

El 26 de agosto de 2012 se dio a conocer la minuta para la negociación del Acuerdo General para la Terminación del Conflicto y la Construcción de una Paz Estable y Duradera, suscrito por las partes en La Habana. Luego de 4 años de arduas negociaciones se firmó el 24 de agosto de 2016 en La Habana el texto del Acuerdo Final de terminación del conflicto armado, texto que fue rubricado por el jefe de Estado y el comandante de las FARC en Cartagena el 26 de septiembre, y sometido a plebiscito el domingo 2 de octubre de 2016, cuyo resultado fue la improbación por una diferencia de 53.908 votos: $49,79 \%$ a favor y $50,21 \%$ por el no ${ }^{6}$.

La improbación del Acuerdo de La Habana por el plebiscito llevó a la reinstalación de la Mesa de La Habana y a una rápida renegociación con los promotores del NO hasta la reelaboración de un «nuevo Acuerdo» con algunos cambios sustanciales, texto que fue firmado por las partes y garantes el 24 de noviembre del 2016 en el Teatro Colón de Bogotá, «Acuerdo» que fue sometido a aprobación por el Senado y luego por la Cámara de Representantes, para quedar aprobado legislativamente el 1 de diciembre de $2016^{7}$, dándole vía libre a su implementación.

Por otra parte, la Corte Constitucional el 13 de diciembre de 2016 dio vía libre a la aprobación de leyes y actos legislativos relacionados con la paz, por un procedimiento abreviado (fast track) contemplado en el Acto legislativo 1 de $2016^{8}$, que a su vez permitía someter por este procedimiento el punto 5 del Acuerdo referente al «Sistema Integral de Verdad, justicia, reparación y No repetición».

Una vez aprobado por esta vía rápida, el Gobierno Nacional mediante Decreto 2052 del 16 de diciembre de 2016 convocó al Congreso de la República a sesiones extraordinarias del 19 de diciembre al 15 de marzo para aprobar una

6 Plebiscito sobre los acuerdos de paz de Colombia de 2016. Disponible en: https:// es.wikipedia.org/wiki/Plebiscito_sobre_los_acuerdos_de_paz_de_Colombia_de_2016 Consultada el 19 de mayo de 2017

7 CARACOL NOTICIAS. Vía libre a la implementación: Congreso refrendó nuevo acuerdo de paz con FARC. Disponible en: http://noticias.caracoltv.com/acuerdo-final/ camara-de-representantes-refrendo-acuerdo-de-paz-con-las-farc. Consultada 19 de mayo de 2017.

8 COLOMBIA. CORTE CONSTITUCIONAL. http://www.corteconstitucional.gov.co/comunicados/No.\%2052\%20comunicado\%2013\%20de\%20diciembre\%20de\%202016.pdf. Consultada el 19 de mayo de 2017 
ley de indulto y amnistía ${ }^{9}$ y el acto legislativo que implementa la justicia especial de paz (JEP). Sometido al Congreso el Acto legislativo, fue aprobado un texto en el Senado ${ }^{10}$ y otro en la Cámara, documentos que fueron conciliados el 28 de marzo de 2017 y que entraron en vigencia una vez promulgados el 4 de abril de $2017^{11}$, reforma constitucional para la cual se halla previsto un control constitucional automático que no suspende la entrada en vigencia.

\subsection{El acto legislativo número 1 del 4 de abril de 2017}

El Gobierno y las FARC manifestaron desde el comienzo de las negociaciones que las víctimas estaban en el centro de los acuerdos, lo que daría una gran legitimidad a lo acordado y una gran esperanza para los más de 6 millones de afectados que ha dejado el conflicto.

El «Sistema Integral de Verdad, justicia, reparación y No repetición» fue previsto desde el 2012 al aprobarse la agenda de negociación Gobierno NacionalFARC, contenido en el Acuerdo Final de La Habana del 24 de agosto de 2016 y firmado en Cartagena el 26 de septiembre de 2016. Improbado el Acuerdo a través del plebiscito el 2 de octubre de 2016, se reformó la composición de la JEP y de nuevo fue incluido como punto número 5 en el nuevo Acuerdo suscrito por el jefe del Estado y el comandante de las FARC en el Teatro Colón de Bogotá el 24 de noviembre de 2016.

El Acuerdo del Teatro Colón relacionado con el «Sistema Integral de Verdad, Justicia, Reparación y No repetición» fue presentado al Congreso de la república como proyecto de acto legislativo transitorio, para ser tramitado a través del mecanismo del fast track; así, una vez se le introdujeron modificaciones y precisiones, fue aprobado como Acto Legislativo nro. 1 del 4 de abril de 2017.

El «Sistema Integral» prevé tres órganos principales:

a. La Comisión para el Establecimiento de la verdad, la convivencia y la no repetición.

9 COLOMBIA. CONGRESO DE LA REPUBLICA. Ley 1820 del 30 de diciembre de 2016. Disponible en: http://es.presidencia.gov.co/normativa/normativa/LEY\%201820\% 20 DEL\%2030\%20DE\%20DICIEMBRE\%20DE\%202016.pdf. Consultada el 19 de mayo de 2017.

10 Senado aprobó conciliación de la Justicia Especial para la Paz. Disponible en: http:// www.eltiempo.com/politica/congreso/senado-aprobo-conciliacion-de-la-justicia-especial-para-la-paz-70322. Consultada el 19 de mayo de 2917.

11 REVISTA SEMANA. Congreso aprueba la Jurisdicción Especial de Paz. Disponible en: http:/ / www.semana.com/nacion/articulo/jurisdiccion-especial-de-paz-camara-de-representantes-aprueba-la-jep/519963 . Consultada el 19 de mayo de 2017. 
b. La Unidad para la búsqueda de personas dadas por desaparecidas en el contexto y en razón del conflicto armado.

c. La Jurisdicción Especial para la Paz.

Además se prevén mecanismos de reparación integral, para la construcción de la paz y de garantías de no repetición.

\subsection{De Cartagena a los «acuerdos del Teatro Colón»}

Una vez improbado el Acuerdo de La Habana-Cartagena en el plebiscito del 2 de octubre de 2016, se adelantaron en forma expedita numerosas reuniones para escuchar los argumentos de los opositores y promotores del NO, y como producto de dichos encuentros se reelaboraron los contenidos de un nuevo Acuerdo en sus seis componentes, quedando modificado el inicial y acordado Acuerdo en relación con el sistema integral de justicia en los siguientes aspectos:

- Se incluyó en el punto 2.2.4, relacionado con la reconciliación, convivencia, tolerancia y no estigmatización, la no victimización en razón de creencias religiosas.

- Se aclaró que la JEP no sustituye la jurisdicción ordinaria. Punto 3.2/3.4.

- Se incluyeron los gestos de búsqueda de personas desaparecidas como parte del Acuerdo, hasta la entrada en funcionamiento de la Unidad de Búsqueda de Personas Dadas por Desaparecidas. Punto 5.

- Se creó un mecanismo de resolución de conflictos de competencias entre la justicia ordinaria y la JEP con una sala incidental conformada por 3 magistrados del Consejo Superior de la Judicatura y 3 magistrados de la JEP. Punto 1.

- Se definió qué se entiende por delitos cometidos por causa, con ocasión o en relación con el conflicto armado. Punto 3.4.4.

- Se introdujo un plazo de 10 años para el funcionamiento de la JEP, más 5 años adicionales únicamente de actividades jurisdiccionales. Punto 3.4.5.

- Se redujo el valor probatorio de las confesiones asociadas a beneficios penales, en el sentido de que no bastará con una confesión sino que será necesario corroborar los hechos con otras pruebas. Punto 1.9.

- Se incluyó dentro del derecho sustantivo aplicable en la JEP el Código Penal Colombiano, Ley 599 de 2000 con sus modificaciones. Punto 3.4.4. 
- Se aclaró que las conductas de financiación no son solo del paramilitarismo sino de cualquier otro actor del conflicto. Punto 3.4.1.1.2.

- Se desarrolló de manera más amplia el monopolio del uso de las armas por parte del Estado y la presunción de legalidad de las acciones de sus agentes. Punto 3.4.1.2.

- Se definió la categoría «agente del Estado». Capítulo 2, art. 46.

- Se remitió a la jurisprudencia interna colombiana para efectos de definir la conexidad entre el delito político y el narcotráfico. Punto 4.

- Se aclaró que las actividades de financiación de la rebelión no podían incluir actividades de lucro personal. Artículo 7.

- Se definió graves crímenes de guerra como aquellos cometidos bajo un plan o política. Artículo 46.

- Se remitió al artículo 28 del Estatuto de Roma en lo relacionado con la responsabilidad del comandante. Punto 11.25

- Se aclaró que serán los magistrados quienes desarrollarán el borrador del código procesal dela JEP, aunque éste deberá ser llevado al Congreso para ser tramitado como Ley. Punto 6.1.6.

- Se estableció que la Sala de Reconocimiento tendrá 2 años, prorrogables por un año más, para recibir todos los informes. Punto 3, artículo 45.

- Se creó la figura de la compulsa de copias justicia ordinaria para los casos de falsos testimonios o falsas acusaciones. Capítulo III, artículo 48 b.

- Se aclaró que también procede la renuncia a la persecución penal frente a los terceros civiles que no hayan tenido una participación determinante en los crímenes más graves y representativos y que se presenten dentro de los 3 primeros años a la JEP. Título III, capítulo I, artículo 43.

- Se estableció la procedencia de la acción de tutela ante la JEP con revisión de la Corte Constitucional. La decisión sobre la procedencia de la revisión de la tutela pasará por una sala de 4 magistrados, 2 de JEP y 2 de la Corte Constitucional. La orden de la Corte deberá ser ejecutada por la JEP. Artículo $5^{\circ}$. 
- Se aclaró que la sección de primera instancia del Tribunal podrá ordenar audiencias públicas con presencia de organizaciones de víctimas para llevar a cabo juicios contradictorios. Punto 5.1.1.1.4.

- Se precisó la causal de revisión de sentencias por parte del Tribunal de la JEP, la cual solo procederá por nuevos hechos o nuevas pruebas. Las sentencias de la Corte Suprema de Justicia solo podrán ser revisadas por esta. Título II, artículo 32.

- Se precisaron los criterios que deberán tener en cuenta los Magistrados al momento de imponer las sanciones de restricción efectiva de la libertad. El tamaño máximo de las zonas donde se llevarán a cabo las acciones restaurativas será de máximo una vereda, y dentro de éstas se deberá establecer el lugar de residencia. Se precisó que las sanciones deberán estar sujetas al cumplimiento de horarios y que deberá haber informes periódicos sobre su cumplimiento. Se estableció que la sanción se empieza a descontar desde la concentración bajo la supervisión del Secretario Ejecutivo de la JEP. Y se estableció que el mecanismo de monitoreo de la sanción estará a cargo de la ONU. Se estableció que la JEP estará compuesta por magistrados y fiscales colombianos. Habrá adicionalmente 10 juristas internacionales que podrán dar su opinión en los procesos como amicus curiae. Título II, artículo 65.

- Se señaló que los Magistrados dela JEP estarán sometidos al régimen disciplinario y de inhabilidades ordinario. Punto 3.4.4, artículo 65.

- Se aclaró que deberán existir protocolos de cooperación entre la Unidad de investigación de la JEP y la Fiscalía General de la Nación. Punto 5.1.

- Se estableció que el secretario ejecutivo de la JEP podrá dictar medidas cautelares. Punto 5.1.2.

- Se incluyó la reconstrucción de los vínculos familiares como elemento del plan de rehabilitación psicosocial.

- Se estableció un compromiso de las FARC de entregar un inventario de bienes y activos para la reparación material de las víctimas durante su proceso de dejación de armas y una obligación del Gobierno de continuar con la búsqueda de los bienes y activos que no hayan sido inventariados por medio de los procedimientos ordinarios.

En cuanto a la implementación, verificación y refrendación de los acuerdos se precisaron los siguientes puntos: 
- Se adicionó un capítulo con los siguientes principios orientadores para la implementación del Acuerdo Final: enfoque de derechos; respeto a la igualdad y no discriminación; enfoque de género; respeto a la igualdad de cultos; integración territorial e inclusión social; fortalecimiento y articulación institucional; profundización de la democracia y «construir sobre lo construido»; eficiencia, eficacia e idoneidad; priorización, transparencia, control social y lucha contra la corrupción; y principio democrático (páginas 192-194).

- Se aclaró el respeto de las competencias de las autoridades territoriales (página 193).

- Se cambió el nombre de la Comisión de Seguimiento para aclarar que esta no tiene funciones de implementación sino de seguimiento, impulso y verificación (página 194).

- Se incluyó el principio de sostenibilidad fiscal para efectos de la implementación del Acuerdo (página 195).

- Se aclaró que la Comisión de Seguimiento no puede afectar el funcionamiento de los distintos órganos del poder público, y se especificó la autonomía del Congreso de la República para el desarrollo de normas (página 199).

- Se eliminó la participación de los países garantes (Cuba y Noruega) y los países acompañantes (Venezuela y Chile) en el proceso de seguimiento a la implementación del Acuerdo (página 210).

- Se corrigió integralmente el acuerdo sobre las 31 emisoras comunitarias, aclarando que serán 20 emisoras F M asignadas a RTVC. Después de 2 años, ECOMÚN tendrá la potestad de programar un tercio de la programación, pero ya no tendrá funciones de administración (página 217).

En lo referente al valor constitucional de los Acuerdos y su relación con el Derecho Internacional se precisó lo siguiente:

- Se estableció que se deroga el artículo referente a la incorporación del Acuerdo como bloque de constitucionalidad, y en vez de ello se tramitará una nueva reforma constitucional que establezca que los contenidos del Acuerdo que correspondan a normas de DIH o a derechos fundamentales serán parámetro obligatorio de interpretación y referente de desarrollo y validez de las normas de implementación de lo acordado. 
- Se elimina la ley aprobatoria del acuerdo especial y por lo tanto el control previo de constitucionalidad del Acuerdo por parte de la Corte Constitucional.

- Se elimina el Acto Legislativo que pretendía incorporar todo el texto del Acuerdo a la Constitución.

- Se eliminan las referencias a que el texto de la ley de amnistía ya estaba definido.

- Se aclara que la JEP sí tendrá ley previa tramitada ante el Congreso ${ }^{12}$.

\subsection{Cambios a la justicia especial de paz (JEP) en el legislativo}

Un aspecto fundamental del Acuerdo de paz no solo para los actores del conflicto sino también para las víctimas lo constituye la creación de la Justicia Especial de Paz (JEP), que quedó aprobada a través del Acto legislativo nro. 1 del 4 de abril de 2017, y a la cual el legislativo le introdujo modificaciones fundamentales respecto a lo establecido en los acuerdos.

La nueva justicia especial de paz se erige como una justicia transicional que juzgará a guerrilleros, agentes del Estado y terceros vinculados al conflicto armado por delitos relacionados con el mismo en forma directa o indirecta. Para su aprobación no contó con el apoyo (votos) de los integrantes del «Centro Democrático", que cuestionan que los integrantes de la guerrillera no "paguen cárcel" en forma efectiva, y que «tal justicia» se prestará para una cacería de brujas contra los agentes del Estado, industriales y empresarios del campo y el Centro Democrático.

Por otra parte, también tuvo oposición de otros sectores políticos como los senadores de la Alianza Verde, Claudia López y Navarro Wolf, por considerar que dicha justicia no garantiza los derechos de las víctimas al prever que podrán acogerse a ella personas que han cometido graves delitos no relacionados con el conflicto, como los militares en relación con los falsos positivos.

La JEP, aprobada en sesión plenaria de las dos Cámaras luego de los textos aprobados separadamente, es una componente del Sistema integral de Verdad, Justicia, Reparación y no Repetición. El sistema está conformado por tres mecanismos: una Comisión de la verdad, la Unidad para la Búsqueda de Personas dadas por Desaparecidas y la Jurisdicción Especial para la Paz

12 "Acuerdo Final para la terminación del conflicto y la construcción de una paz estable y duradera". FARC-EP, Teatro Colón, Bogotá, 24 de noviembre de 2016. 
(JEP), y las medidas de reparación integral para la construcción de paz y las garantías de no repetición.

Mientras el Tribunal de Paz administrará justicia de manera «transitoria» sobre conductas cometidas antes del 1 de diciembre de 2016 «por causa, con ocasión o en relación directa o indirecta con el conflicto armado», la Comisión tendrá un carácter extrajudicial y su misión es indagar sobre la verdad de lo que ocurrió en 52 años de confrontaciones.

La activación del Fast Track permitió acelerar y aprobar en forma expedita el Acto Legislativo que acabó siendo el mismo que radicó el Gobierno en el Congreso. En total, el Gobierno avaló 83 proposiciones, que según el ministro del Interior, Juan Fernando Cristo, modificaron todo el articulado del proyecto ${ }^{13}$.

Algunos de los cambios que se hicieron al acto legislativo que se consideraron esenciales son los siguientes:

\subsubsection{Participación política de las FARC}

Uno de los aspectos principales de las negociaciones de paz era convertir la guerrilla de las FARC en actor político, incluso pese a los delitos que hubieren cometido o de los que se les acusará. Con la aprobación del Acto legislativo esa premisa quedó condicionada. Los miembros de las FARC que quieran aterrizar a la vida política lo tendrán que hacer con el aval del Tribunal de Paz que certificará si el individuo contribuyó o no con los puntos dispuestos en el Sistema Integral de Verdad Justicia, Reparación y No Repetición. La proposición del senador Carlos Antonio Galán (Cambio Radical) disolvió una parte de las críticas que apuntaban a que los miembros de esa guerrilla -especialmente máximos responsables- puedan participar en política y ser elegidos sin cumplir con los compromisos pactados.

Lo aprobado establece limitaciones al propósito de las FARC de participar ampliamente y sin limitaciones en política, el cual ha sido unos de los argumentos de los actores guerrilleros para justificar la lucha armada. Al respecto se pronunció el dirigente guerrillero IVÁN MÁRQUEZ una vez supo que la participación en la arena política tendría que contar con un aval individual del Tribunal de Paz, donde certifique que cumplió con lo diseñado en el Sistema

13 COLOMBIA. PRESIDENCIA DE LA REPUBLICA. JEP y Justicia Transicional son ejes que garantizan implementación de acuerdos: Ministro del Interior. Disponible en: http:/ / es.presidencia.gov.co/noticia/170314-JEP-y-Justicia-Transicional-son-ejes-que-garantizan-implementacion-de-acuerdos-Ministro-del-Interior. Consultada el 19 de mayo de 2017. 
de Verdad, Justicia, Reparación y No Repetición: «Por ningún motivo se puede afectar la Participación Politica, esencia del Acuerdo de Paz. Su modificación es como una puñalada en el corazón» ${ }^{14}$.

\subsubsection{Prohibición de la extradición}

Otro de los aspectos importantes que modifica la Constitución es la prohibición de la extradición para quienes se acojan o queden cobijadas por la JEP, sin importar la naturaleza de los delitos y si estos se cometieron dentro o fuera del país, y en consecuencia también se prohíbe la detención con fines de extradición.

\subsubsection{Responsabilidad de mando en operaciones militares}

La previsión de que los mandos superiores respondieran por los crímenes de guerra y delitos de lesa humanidad en los términos establecidos en el Estatuto de la Corte Penal Internacional (CPI) fue motivo de preocupación y rechazo de los estamentos militares activos y de la reserva, lo que llevó a que se reelaborara este articulado estableciendo que la responsabilidad del mando no se podrá fundar exclusivamente en el rango, la jerarquía o el ámbito de jurisdicción, sino en el control efectivo de la respectiva conducta y en el conocimiento basado en la información a su disposición.

Este tema respecto a las FARC no quedó incluido en el Acto Legislativo que da vida a la Jurisdicción Especial de Paz, y al respecto se dijo que se discutirá en el trámite de Ley Estatutaria que reglamentará el funcionamiento de la justicia transicional que se adoptó para investigar y juzgar las graves violaciones de derechos humanos y graves infracciones al Derecho Internacional Humanitario (DIH) en contexto y a razón del conflicto armado.

\subsubsection{Justicia Especial de Paz para activos y desertores de las FARC}

La JEP estaba prevista para los integrantes activos de las FARC, pero con el texto aprobado se pueden acoger a ella los antiguos integrantes de las FARC que desertaron y se acogieron a la Ley de Justicia y Paz.

La Jurisdicción Especial para la paz tendrá la competencia sobre los casos de los miembros de esa guerrilla que hayan sido condenados, procesados o in-

14 EUROPA PRESS. Uribe acusa al Gobierno de «entregar la Justicia y la Constitución» a las FARC. Disponible en: http:/ / www.europapress.es/internacional/noticia-uribe-acusa-gobierno-entregar-justicia-constitucion-farc-20170315064235.html. Consultada el 19 de mayo de 2017. 
vestigados antes del primero de diciembre del 2016 aunque no aparezcan en las listas que presente el grupo.

$\mathrm{Al}$ respecto ya hay pronunciamiento de la Corte Suprema de Justicia al resolver en segunda instancia una decisión del Tribunal Superior de Bogotá, que establece que dichos excombatientes sí se pueden acoger siempre y cuando renuncien a la Ley de Justicia y Paz a la cual se hallaban acogidos anteriormente. Al respecto la Corte precisó con ponencia del magistrado Jorge Mayorga Rodríguez, y criticó posición institucional de la Fiscalía y explicó que los guerrilleros desmovilizados que estén en un proceso con Justicia y Paz sí pueden acceder a una amnistía o indulto, siempre y cuando renuncien a su proceso en Justicia y Paz.

Dice el alto tribunal que la interpretación tanto de la Fiscalía como la del Tribunal Superior de Bogotá es equivocada «porque se apoya en una interpretación fragmentada de la normatividad aplicable al caso, pues omite a los diversos destinatarios de la ley 1820 de 2016»15.

\subsubsection{Limitación de terceros partícipes del conflicto}

Uno de los objetivos del «sistema integral de justicia» es establecer la responsabilidad de todos los partícipes directos e indirectos en los crímenes cometidos en relación con el conflicto armado y la financiación de los actores irregulares; para ello se le daba facultad a la JEP de vincular y procesar a los terceros civilmente responsables de financiamiento de guerrilla o paramilitarismo, una vez se obtuviera información al respecto.

El uribismo y Cambio Radical a través del senador Germán Varón Cotrino lograron modificar los criterios de investigación relacionados con los criterios de vinculación a las investigaciones penales acentuando la necesidad de que la justicia especial tenga en cuenta más material probatorio, no solo un testimonio, a la hora de citarlos. De conformidad con lo anterior, el nuevo Tribunal deberá concentrar sus esfuerzos en grandes responsables, por lo que muy pocos terceros terminarán en ese escenario y más cuando se advirtió que su intervención será voluntaria siempre y cuando no estén estrechamente vinculados con infracciones al Derecho Internacional Humanitario de manera «sistemática».

15 EL ESPECTADOR. La Corte Suprema se pronuncia por primera vez en un caso que involucra a la JEP. Disponible en: http://www.elespectador.com/noticias/judicial/lacorte-suprema-se-pronuncia-por-primera-vez-en-un-caso-que-involucra-la-jep-articulo691355.- Consultada el 19 de mayo de 2017. 
La vinculación de financiadores y determinadores (ganaderos, empresarios del campo y la ciudad) de graves y numerosos crímenes contra las víctimas tuvo amplio rechazo por los sectores opuestos a los acuerdos de paz, porque, paradójicamente, ellos han estado cubiertos por total impunidad, que amenazaba romperse al llegar a la JEP bajo el compromiso de reconocer los hechos y la responsabilidad sobre las 13.000 denuncias de financiación y participación del paramilitarismo y sus innumerables crímenes que se revelaron en la Fiscalía del doctor Montealegre Linet, pero que el actual fiscal general, MARTÍNEZ NEIRA, se niega a vincularlos a investigación ${ }^{16}$.

\subsubsection{Investigación de delitos de ejecución continuada}

Se precisó en el Acto legislativo que en cuanto a los delitos de ejecución continuada, como los relacionados con el lavado de activos, la Fiscalía General de la Nación tendrá competencia para investigar y llevar a juicio a quienes no registren bienes adquiridos ilícitamente, bienes que podrán ser reportados durante el tiempo que duren las zonas veredales. Al respecto quedó establecido que los que no se registren quedarán bajo jurisdicción de la justicia ordinaria. En ese sentido, la Fiscalía tendrá competencia de los delitos de ejecución continuada que se continúen más allá de la certificación de la completa desmovilización.

\subsubsection{Competencia sobre delitos cometidos durante el proceso de desmovilización}

Se estableció en el acto legislativo de la JEP que a través de la ley reglamentaria se precise cuáles delitos cometidos por integrantes de las FARC entre la aprobación del Acuerdo (1 de diciembre de 2016) y la total desmovilización serán competencia del tratamiento especial de JEP, que «estén estrechamente vinculadas al proceso de la dejación de armas desarrolladas desde el primero de diciembre de 2016 hasta el momento en que finalice el proceso de extracción de las armas por parte de las Naciones Unidas conforme a lo dispuesto en el Acuerdo Final».

\subsubsection{Competencia sobre el delito de Narcotráfico}

En lo referente al delito de narcotráfico el acto legislativo determinó que cuando este se halla relacionado con la financiación y desarrollo de la rebelión puede ser tenido como conexo al delito político, pero no cuando tiene fines de enriquecimiento personal. Respecto al delito de cultivos ilícitos de

16 EL TIEMPO. Víctimas de extorsión no tienen deuda con la justicia: Fiscal General. http:/ /www.eltiempo.com/politica/proceso-de-paz/fiscalia-dice-que-victimas-de-extorsionno-estaran-en-justicia-transicional-45069. Consultada el 19 de mayo de 2017. 
pequeños productores se establece que la ley reglamentaria de la JEP regulará el tratamiento penal diferenciado en lo relativo a la erradicación voluntaria de cultivos ilícitos y cuál será competencia y a partir de qué fecha y condiciones de la justicia ordinaria.

\subsubsection{Enfoque de género en la Justicia Especial de Paz (JEP)}

El acto legislativo estableció que el Sistema Integral de Justicia tendrá un enfoque territorial y de género que corresponda a las características particulares de la victimización en cada territorio y en especial a la protección y atención prioritaria de las mujeres y niños víctimas del conflicto armado. El enfoque de género y diferencial se aplicará a todas las fases y procedimientos del sistema. En especial a todas aquellas mujeres que han padecido o participado en el conflicto.

\subsubsection{Exclusión de disidentes y reincidentes de la Justicia Especial de Paz (JEP)}

El acto legislativo de creación de la JEP excluyó de la competencia y tratamientos especiales a los desertores y disidentes de las FARC que continúen por fuera de la ley. De ninguna forma podrán beneficiarse del régimen especial de penas y libertades contempladas para los miembros de la organización insurgente. En ese sentido, el sistema de justicia transicional solo aplicará para quienes suscriban un acuerdo de paz con el Gobierno. En el caso de los reincidentes no "convivirán los beneficios que otorga la justicia transicional y el delito»; por eso serán objeto de doble sanción: por un lado con la justicia ordinaria y por el otro podrán ser objeto de la pena máxima prevista por la JEP de 20 años.

\subsubsection{La jurisdicción Indígena y la Justicia Especial de Paz (JEP)}

Los conflictos de competencia entre la Jurisdicción Especial de Paz y la Jurisdicción Especial Indígena serán dirimidos por una sala incidental conformada por dos magistrados de la salas o secciones de la Jurisdicción Especial de Paz no afectadas por dicho conflicto jurisdiccional y dos autoridades tradicionales del pueblo indígena que ejerció o está ejerciendo jurisdicción en el caso concreto. La decisión se adoptará en la sala incidental con mayorías simples y que en caso de no alcanzarse una minoría en aplicación del carácter preferente de la jurisdicción Especial para la Paz resolverá el presidente de esa jurisdicción.

\subsubsection{Funcionamiento de la Unidad de Búsqueda de Desaparecidos}

Los órganos del Estado deberán brindar toda la colaboración que requiera la Unidad de Búsqueda de Desaparecidos. Se deberá promover la participación 
de las víctimas y sus organizaciones en todas las fases del proceso de búsqueda, localización, recuperación, identificación y entrega digna de restos de personas dadas por desaparecidas en el contexto y en razón del conflicto armado.

\subsection{Destinatarios de la justicia especial de paz}

Siete son los grupos de actores y partícipes que concurrirán a la JEP, sobre los cuales corresponde analizar si su participación y compromisos son simétricos y equitativos:

a. Los integrantes de la guerrilla de las FARC-EP, sus milicianos y apoyos urbanos que estén en la lista elaborada por las FARC.

b. Los integrantes de la fuerza pública (ejército-policía), partícipes en delitos contra el Derecho Internacional Humanitario.

c. Terceros que hayan participado en la financiación o realización eficaz y decisiva en la comisión de graves crímenes de guerra y de lesa humanidad, delitos sexuales y secuestro.

d. Agentes del Estado (integrantes de las corporaciones públicas y otros empleados o trabajadores públicos u oficiales), partícipes en delitos relacionados con el conflicto.

e. Integrantes de grupos armados ilegales que hayan firmado el proceso de paz y que no se hayan acogido a los anteriores sistemas de justicia transicional.

f. Personas que hayan sido investigadas o juzgadas o lo estén siendo por pertenecer a las FARC, así no se hallen en las listas elaboras por estas.

g. Los integrantes de movimientos sociales detenidos por participar en la protesta y procesados por delitos afines con esta y acusaciones fraudulentas contra personas vinculadas a las organizaciones sociales.

\subsection{Las víctimas y los actores responsables en los «acuerdos del fast track»}

Los derechos de las víctimas a la verdad, a la justicia, a la reparación y a la no repetición se ven afectados por el texto aprobado de la JEP por el Congreso de la república, modificando el acuerdo pactado, el cual ya contenía previsiones que resultaban preocupantes en razón a garantizar plenamente los derechos de ellas. 
El texto de la JEP, aprobado como acto legislativo, contiene numerosas previsiones legales que favorecen que amplios sectores responsables de innumerables crímenes de Estado y contra los sectores populares se puedan acoger a la JEP y buscar ser beneficiarios de los tratamientos especiales por graves crímenes de «lesa humanidad», de guerra, violaciones de derechos humanos, y aún delitos comunes, todo en detrimento del amplio espectro de víctimas que ha dejado el conflicto armado.

El alcance de las «licencias» o previsiones que permiten a los victimarios, especialmente a los vinculados al Establecimiento y su defensa, es una labor que apenas comienza, ya que, por una parte, se halla aún pendiente su desarrollo a través de una ley reglamentaria, y por otro, dependerá de la interpretación que se dé en la práctica, en el ejercicio profesional, ante las pretensiones de los defensores de los victimarios, que distarán de ser razonables y exigirán una interpretación y aplicación garantista de los derechos de las víctimas, no de los perpetradores.

Algunos de los aspectos más relevantes que resultan problemáticos y que se advierten antes de la aprobación de la ley estatutaria de la JEP hacen referencia a las siguientes instituciones:

\subsubsection{Acceso de terceros partícipes de graves crímenes en el contexto del conflicto armado}

La superación de impunidad que en forma constante ha cubierto la mayoría de los graves crímenes cometidos en el marco del conflicto armado, y que se buscaba con la vinculación de terceros, que no habiendo sido parte de las FARC o de las fuerza pública, hubieran contribuido en alguna al desarrollo del conflicto y la comisión de delitos relacionados con el mismo, se halla prevista de tal manera que no contribuirá en buena parte al conocimiento de la verdad, y a la vinculación de todos los responsables, por una parte, y al ingreso a la JEP de otros responsables de delitos no relacionados directamente con el conflicto, que conllevará una gran dosis de impunidad sobre una inmensa cantidad de delitos cometidos en beneficio de intereses particulares ajenos al conflicto.

En cuanto a la vinculación de terceros responsables, de los cuales se buscaba que dijeran toda la verdad, se establece en el artículo 16, que solo tendrán acceso a la JEP cuando «hubieran tenido una participación activa o determinante en la comisión» de los delitos allí relacionados, cometidos en forma «sistemática», entre ellos el «acceso carnal violento y otras formas de violencia sexual». 
Por otra parte, y en forma grave, se prevé que la vinculación de estos terceros y la decisión sobre los mismos «no podrán fundamentarse exclusivamente en los informes recibidos por la JEP, sino que deberán corroborarlos a través de otros medios de prueba» ${ }^{17}$.

\subsubsection{Tratamientos diferenciales para miembros de la Fuerza Pública}

Según el acuerdo final, la Jurisdicción Especial para la Paz (JEP) aplicaría como fuente del derecho sustancial el Código Penal colombiano, las normas de derechos humanos (DH), el Derecho Internacional Humanitario (DIH) y el Derecho Penal Internacional (DPI), para determinar la sanción de las personas que se hayan visto envueltas en hechos relacionados con el conflicto armado.

Sin embargo, el Acto Legislativo establece una regla particular para la Fuerza Pública, sin razón alguna. Por un lado, en estos casos se omitirá lo dicho por el Derecho Penal Internacional, las normas de derechos humanos, y se aplicará el Penal colombiano «vigente al momento de la comisión del hecho». La pretensión del estamento militar y los abogados que ejercen a su servicio han buscado durante los procesos que algunos delitos -como la desaparición forzada de personas-, como los ocurridos en la retoma del Palacio de Justicia, no constituyen delitos ni violación del Derecho Internacional Humanitario porque para entonces no se había tipificado en el derecho penal colombiano. Esta pretensión constituye una muestra horrorosa de lo que se puede pretender a través de dicha interpretación.

La comunidad nacional e internacional de derechos humanos ha advertido sobre las consecuencias adversas que este tipo de previsión puede ocasionar al derecho de las víctimas. Sobre este aspecto se pronunció la organización no gubernamental De justicia: "No existe justificación para que esto sea así. Primero: porque Colombia ha reconocido los tratados de Derecho Penal Internacional (como el Estatuto de la Corte Penal Internacional) que aplican a todos los responsables de cometer crimenes internacionales (genocidio, crimenes de lesa humanidad y de guerra). Y segundo: porque si al momento de ocurrir el crimen este no estaba calificado como tal en la legislación penal colombiana, podrían quedar por fuera hechos que actualmente el Estado tiene la obliga-

17 CONGRESO NACIONAL. Acto Legislativo No. 1 del 2017, art. \# 16. Disponible en: http:/ / es.presidencia.gov.co/normativa/normativa/ACTO\%20LEGISLATIVO\% 20N\%C2\% B0\%2001\%20DE\%204\%20DE\%20ABRIL\%20DE\%202017.pdf. Consultada el 19 de mayo de 2017 
ción de juzgar y sancionar según el DIDH y el DIH, como el genocidio o la desaparición forzada». ${ }^{18}$

El Acuerdo fijó unos principios mínimos para juzgar a los perpetradores: que se sancione a todos los responsables del conflicto con unas reglas similares y un tratamiento equilibrado.

Pero el acto legislativo tiene dos raseros distintos para excombatientes de la guerrilla y la Fuerza Pública. De acuerdo con la crítica de Dejusticia, para estos últimos, la Jurisdicción Especial para la Paz no solo tendrá competencia para juzgar sus actos relacionados con el conflicto armado, sino que podrá tratar otro tipo de conductas que no tienen una relación muy clara con el conflicto.

En otras palabras, los miembros de la Fuerza Pública podrán acceder al tratamiento especial de la JEP (en lugar de hacerlo a través de la justicia ordinaria, que es más severa), para que se juzguen otros delitos como aquellos en los que existía ánimo de obtener enriquecimiento personal, o aquellos cometidos por una persona que, por haber pertenecido a la Fuerza Pública, adquirió mayores habilidades al haber participado en el conflicto armado. Por ejemplo, se podrían ver beneficiados por esto los militares que se vieron envueltos en grupos delincuenciales donde desplegaron acciones armadas o, incluso, espionajes como la «operación Andrómeda», en la que miembros de la Fuerza Pública utilizaron su conocimiento en inteligencia propia de la guerra para ponerlo a disposición de la persecución política.

\subsubsection{Responsabilidad de mando en contravía del Derecho Internacional Hu- manitario y Derecho Penal Internacional}

La responsabilidad del mando es una figura del derecho internacional que permite judicializar a un comandante militar por las atrocidades cometidas por sus subalternos bajo determinados requisitos. La regla general es que si el comandante no ordenó ni participó en esos actos, debe responder por ellos si pudiendo hacerlo, no evitó que estos ocurrieran o se abstuvo de sancionar a los responsables. En este tema hay varios reparos:

En el artículo 23 de la JEP, se establece que a ella podrán concurrir los integrantes de la Fuerza Pública que hayan cometido delitos «por causa, con ocasión

18 DEJUSTICIA. Cinco puntos que preocupan sobre la Jurisdicción Especial para la Paz. En: El Espectador. Disponible: http:/ / colombia2020.elespectador.com/pais/cinco-puntos-quepreocupan-sobre-la-jurisdiccion-especial-para-la-paz. Consultada el 19 de mayo de 2017. 
o en relación directa o indirecta con el conflicto armado y sin ánimo de obtener enriquecimiento personal ilícito».

La preocupación de las víctimas y de juristas de las organizaciones de derechos humanos y universidades es que a los responsables de numerosos y graves delitos no relacionados directamente con el conflicto, como los llamados falsos positivos, el cohecho que llevó al senador Álvaro Uribe Vélez a la presidencia por segunda vez, e incluso el acceso carnal abusivo se les aplique el tratamiento especial que la JEP establece y obtengan, así, desde la libertad inmediata hasta inmerecidas rebajas de penas que en muchos casos ya se les han impuesto por la justicia ordinaria, no por la justicia penal militar.

De la anterior manera se revive un fuero penal militar especial transitorio que cobijaría todos los delitos cometidos por los integrantes de la fuerza pública antes del 1 de diciembre de 2016.

El 3 de mayo de 2017, el Ejecutivo Nacional expidió el Decreto 706 de 2017 por el cual se da un tratamiento especial a los integrantes de la fuerza pública que se hallen detenidos por delitos relacionados directa o indirectamente con el conflicto armado, o tengan órdenes de captura en su contra, a los cuales se les puede dar libertad o sustituir la medida de aseguramiento por otra, o suspender las órdenes de captura con la sola suscripción de un acta de compromiso ante el operador judicial que dispuso la detención o la orden de captura.

Un día después de expedido este decreto, el 5 de mayo de 2017, el Juzgado 21 de Ejecución de Penas de Bogotá ordenó la libertad del general (r) Jaime Humberto Uscátegui, condenado a 37 años por la masacre de Mapiripán en el Meta. El exgeneral fue beneficiado con la libertad transitoria una vez suscrita el acta de compromiso de acogerse a la Justicia Especial para la Paz (JEP) para la «revisión» de su proceso, para lo cual se dispone con su abogado a «preparar mi defensa ante la Jurisdicción Especial de Paz» ${ }^{19}$.

3.7.4. Por otra parte, se considera que solamente existe mando y control efectivo si hay una relación de subordinación, "de tipo jurídica y de facto", entre el superior y quien cometió el crimen. La exigencia de esos requisitos formales y materiales para comprobar la responsabilidad del mando desconoce el Derecho Penal Internacional. Según este, la existencia de mando efectivo sobre las tropas se determina probatoriamente,

19 RCN RADIO. En libertad el general Jaime Humberto Uscátegui tras acogerse a la JEP. Disponible en: http://www.rcnradio.com/nacional/libertad-general-jaime-humbertouscategui-tras-acogerse-la-jep/ . Consultado 13 de mayo de 2017. 
estableciendo si el superior podía o no prevenir la atrocidad cometida por sus subalternos.

Si esto no cambia, es improbable que en Colombia se llegue a condenas efectivas a los máximos responsables de las atrocidades que ha vivido el país en el último medio siglo. Y será difícil que se dé una condena como la que la Corte Penal Internacional le impuso en junio del 2016 a Jean-Pierre Bemba, ex vicepresidente de la República Democrática del Congo. Bemba fue encontrado culpable porque las tropas del Movimiento para la Liberación del Congo, que estaban bajo su mando, cometieron crímenes de guerra y de lesa humanidad en el país vecino: la República Centroafricana. Aunque él no tenía mando legal sobre la República Centroafricana, sí tenía mando material sobre las tropas que operaban allí.

Lo anterior debe tenerse en consideración, pues de lo contrario el Tribunal Penal Internacional para la ex Yugoslavia no hubiese podido condenar a Zdravko Muciæ por su responsabilidad de mando sobre los crímenes que cometieron sus subordinados en la prisión Ėelebiæi (usada durante la guerra de Bosnia de 1992 para recluir ilegalmente a prisioneros serbios). Muciæ no recibió nombramiento formal como comandante de la prisión. Pero el Tribunal encontró que tenía control de hecho sobre sus subordinados. Por ejemplo, un periodista bosnio aseguró que había ingresado a esta prisión con un permiso de Muciæ.

\subsubsection{El texto de la JEP únicamente permite juzgar a un superior si se prueba que este sabía que sus subordinados estaban cometiendo o iban a come- ter un crimen. Pero el Derecho Internacional Humanitario y el Derecho Penal Internacional también exigen que se juzgue a superiores si hay evidencia de que estos poseían información que les "permitiera concluir, en las circunstancias del momento, que sus subordinados no estaban cometiendo o iban a cometer violaciones».}

Así ocurrió en el mencionado caso de Muciæ. El tribunal de la ex Yugoslavia argumentó que este comandante supo o tenía razones para saber que sus subordinados estaban cometiendo crímenes en Èelebiæi. Los crímenes ocurridos allí fueron tan frecuentes y notorios que no había manera de que no supiera o no escuchara de ellos.

Este punto y el anterior han sido los argumentos utilizados por el general Uscátegui y su defensa, que han argumentado que el general no tenía mando sobre Mapiripán y que por lo tanto no tenía responsabilidad pese a que había sido advertido sobre la llegada de los paramilitares en avión y su desplazamiento a Mapiripán, donde durante dos días se cometió la masacre sin ninguna intervención de la fuerza pública. 
3.7.6. En la norma aprobada no está explícito que la responsabilidad del mando también aplicará a los jefes guerrilleros, como lo establece el acuerdo final. Este vacío ha llevado a que algunos infieran que solo aplicará a la fuerza pública y no a la guerrilla. Por esto, es fundamental que se incluya este punto explícitamente, pues a la guerrilla se le aplicará un derecho penal y unos principios mucho más drásticos, como el desarrollado por Roxin ${ }^{20}$, sobre los aparatos organizados de poder, en el que los mandos responden por todos los crímenes cometidos por sus subordinados.

Algo similar sucede con los gobernadores o alcaldes, que son la máxima autoridad de policía en sus jurisdicciones y fueron copartícipes y corresponsables en numerosas acciones de la fuerza pública que conllevaron graves crímenes contra el DIH.

\subsubsection{Excepción al pago de perjuicios por integrantes de la fuerza pública}

En el capítulo VII del Acto Legislativo se establecen las normas aplicables a la fuerza pública. En el artículo 26 del Acto Legislativo para La Paz se establece que «En el caso de miembros de la Fuerza Pública que hayan cometido conductas punibles por causa, con ocasión o en relación directa o indirecta con el conflicto armado interno, no procederá la acción de repetición y el llamamiento en garantía establecidos en el artículo 90 de la Constitución Política. En todo caso, deberán contribuir al esclarecimiento de la verdad, a la reparación no monetaria de las víctimas y garantizar la no repetición.»

En ninguna parte de este articulado se hace referencia a que los integrantes de la fuerza pública deban contribuir con sus bienes a la reparación de las víctimas; incluso en el artículo 25 que establece las acciones para obtener redenciones, subrogados penales o beneficios adicionales en la privación de la libertad en las sanciones ordinarias no se enumera las reparaciones entre ellas,

20 BAILONE, Matias. El autor de escritorio y el ejecutor fungible: una modesta aproximación a la teoría de Claus Roxin. "Uno de los temas centrales a la hora de hablar de la influencia de Claus Roxin, es el de la teoría de la autoría mediata a través de los 'aparatos organizados de poder'. Esta teoría la elaboró Claus Roxin en 1963, en base al juicio al que se lo sometió al nazi Adolf Eichmann, capturado en la Argentina, en el Tribunal de Jerusalén. Y fue en estas latitudes donde se produjo una de las primeras recepciones jurisprudenciales de la teoría roxiniana: con motivo del juicio a la junta militar argentina en 1983. Luego la acepta el Tribunal Supremo Alemán con motivo del conocido caso de los guardianes del muro". Disponible en: http://www.terragnijurista.com.ar/doctrina/autoria_mediata.htm. Consultada 4 de abril de 2017. 
quedando establecido que no se halla contemplada esta condición o requisito para los beneficios allí establecidos.

En todo caso habrá que aclararse en la ley reglamentaria o por vía de revisión de constitucionalidad si los integrantes de la fuerza pública deberán responder con sus bienes a las víctimas en la JEP, como los demás actores y partícipes, o definitivamente van a quedar excluidos de estas obligaciones.

\subsubsection{Conflicto armado, genocidio, víctimas y actores}

El genocidio es el más grave delito internacional que los Estados tienen la obligación de combatir, garantizando la no impunidad sobre sus autores como garantía de la no repetición. El sociólogo argentino DANIEL FEIERSTEIN, quien ha investigado durante más de treinta años masacres y holocaustos en diferentes contextos históricos, considera que en Colombia se han cometido varios genocidios. Al respecto precisa:

Yo creo que en Colombia hubo varios genocidios. Lo que pasa es que no todo el conflicto armado fue el genocidio. Me parece que ese es el tema más delicado de este país, donde hubo simultáneamente un conflicto armado y un genocidio. El conflicto armado y el genocidio son dos cosas distintas. La guerra tiene determinadas características y determinadas lógicas que tienen que ver con la confrontación de distintos sectores sociales, mientras que el genocidio es otro tipo de proyecto que se propone la destrucción de la identidad ${ }^{21}$.

Este autor considera que la guerra requiere de un proceso de paz y reconciliación, pero que el genocidio no puede saldarse con impunidad. De ahí que resulta grave y preocupante que en el Acuerdo no se identificó este crimen en su real dimensión, por lo que no se previeron normas específicas para sancionar a los responsables para que no haya impunidad y garantizar la no repetición:

Ha ocurrido en distintos casos históricos, como el nazismo, lo mismo que pasa en Colombia: la guerra y el genocidio coinciden, es decir, ocurren en el mismo período histórico. Lo importante a nivel político es poder distinguir un momento del otro. Porque una guerra requiere un proceso de paz y de reconciliación entre quienes libraron la guerra, pero un genocidio no puede saldarse con impunidad ni reconciliación. Me parece que es fundamental distinguir esos dos procesos. Colombia

21 FEIERSTEIN, Daniel. En Colombia hubo conflicto armado y genocidio. Disponible en: http:/ / www.elespectador.com/noticias/cultura/hasta-que-el-estado-no-aclare-susnexos-con-el-paramilitarismo-el-genocidio-en-colombia-va-continuar-articulo-692264. Consultado 13 de mayo de 2017. 
vivió distintos momentos de prácticas genocidas, los dos más fuertes fueron toda la politica dirigida a los sectores rurales, y sobre todo comunidades indígenas $y$ campesinas, por parte del aparato estatal y los paramilitares, y luego, el caso más tratado jurídicamente, el de la Unión Patriótica. Son dos procesos que dejan claro su contenido genocida $y$, si bien se encuentran articulados con la guerra, sus objetivos no son los objetivos de la guerra. El aniquilamiento de la Unión Patriótica se hace en el contexto de un proceso de paz, cuando uno de los bandos en conflicto decide incorporarse al espacio político y transformarse en un partido. Por lo tanto, hubo una fuerte convicción del Estado para impedir esa posibilidad y lo hizo a través del terror y la persecución sistemática de sus miembros. Lo mismo ocurrió con el intento de transformar la estructura productiva colombiana a partir del ataque a determinadas comunidades indígenas o comunidades campesinas. Creo que el gran desafío del caso colombiano es poder distinguir entre estas dos situaciones. Creo que requieren políticas distintas ${ }^{22}$.

El autor concluye que es necesario comprender las diferencias entre el conflicto armado y el genocidio, que una sociedad no puede avanzar si no se sanciona el genocidio, lo cual es necesario para evitar que vuelva ocurrir:

«Una sociedad no puede avanzar con la impunidad de genocidas. El tejido social no puede sanar si los responsables de prácticas genocidas no se hacen responsables de las consecuencias de sus acciones. Si no son atravesados por el aparato judicial, si no son sometidos a la ley, es imposible que esas conductas no se sigan repitiendo» ${ }^{23}$.

Finalmente, se debe resaltar que en lo pactado y en el desarrollo normativo hasta ahora aprobado, se ha reconocido que el Acuerdo tiene como principio la «centralidad en las víctimas» y reconoce igualmente que hay millones de víctimas colombianas producto del conflicto armado que se vieron obligadas a exilarse y hoy residen en el extranjero. Esto ha llevado a que 60 organizaciones sociales y de derechos humanos agrupadas en la Coordinación Colombia-Europa-Estados Unidos recomienden al Comité de Escogencia de los magistrados de la JEP, que es el mecanismo escogido por las FARC-EP y el Estado colombiano para seleccionar en forma autónoma e independiente los integrantes de las instancias creadas en el marco del «Sistema Integral de Verdad Justicia, Reparación y No repetición», formalizado mediante el Decreto 587 de 2017,24 que las

22 Ibíd.

23 Ibíd.

24 COLOMBIA. PRESIDENCIA DE LA REPUBLICA. Decreto 587 de 2017. Disponible en: http:/ /es.presidencia.gov.co/normativa/normativa/DECRETO \%20587\%20DEL\%2005\% 20DE\%20ABRIL\%20DE\%202017.pdf. Consultado 19 de mayo de 2017. 
víctimas «deben tener la oportunidad y los espacios para hacer reparos a la posible selección de candidatos propuestos con base en hechos probados de actuaciones en contra de los derechos de las víctimas y los derechos humanos. Esto supone -concluye este acápite- que las organizaciones puedan hacer llegar los fundamentos de sus observaciones al Comité en forma adecuada y oportuna» 25 , y que las personas seleccionadas «tengan conocimiento y/o experiencia en temas de refugio, exilio y desplazamiento transfronterizo, con enfoque de género y diferencial»26, como garantía de que a éste amplio sector de víctimas se les reconozca sus derechos.

Los integrantes que este Comité de Escogencia debe seleccionar corresponden a las siguientes entidades:

- Magistrados de la Jurisdicción Especial de Paz.

- El director de la unidad de investigación y acusación de la JEP.

- Los juristas expertos extranjeros que actuarán en calidad de Amicus Curiae en la JEP.

- El secretario ejecutivo de la JEP.

- El presidente de la JEP.

- Los once integrantes de la Comisión para el esclarecimiento de la Verdad, la Convivencia y la No repetición (CEV), incluido su presidente.

- El director de la Unidad de Búsqueda de Personas dadas por Desparecidas en el contexto y en razón del conflicto armado (UBPD).

- Una terna de candidatos a director de la Unidad de Investigación y desmantelamiento de las organizaciones criminales contemplada en el numeral 3.4.4 del Acuerdo Final. ${ }^{27}$

25 COORDINACION COLOMBIA EUROPA ESTADOS UNIDOS. Propuesta de organizaciones sociales y de derechos humanos sobre criterios que deben regir el mecanismo de selección y escogencia de los candidatos a hacer parte del sistema integral de Verdad, Justicia, Reparación y No Repetición. Bogotá: CCEEU. 2017, p 6.

26 Ibíd., p 12.

27 PRESIDENCIA DE LA REPUBLICA. Decreto 587 de 2017. Disponible en Disponible en: http:/ / es.presidencia.gov.co/normativa/normativa/DECRETO \% 20587\%20DEL\% 2005\%20DE\%20ABRIL\%20DE\%202017.pdf. Consultado 19 de mayo de 2017. 


\section{OTROS ÓRGANOS DEL SISTEMA INTEGRAL DE VERDAD, JUSTICIA, REPARACIÓN Y NO REPETICIÓN Y LUCHA CON- TRA EL PARAMILITARISMO}

El Acto legislativo que crea la JEP consagra la creación de dos organismos independientes de los previstos para justicia penal transicional que buscan garantizar no solo la paz sino la justicia (entendida no solo como sanción penal), la verdad y las garantías de no repetición, instituciones que se analizarán en posteriores avances de la investigación, por contener estos componentes no solo la creación del órgano o aparato institucional como tal, sino su composición, funciones y objetivos, por lo que se hace necesario desarrollarlos en investigación aparte, pero que por ahora se mencionan.

El Acto Legislativo introdujo la participación de la Procuraduría General de la Nación, la Defensoría del Pueblo y la Contraloría General de la República «para hacer seguimiento a la ejecución de los recursos y al cumplimiento de las metas propuestas en el acuerdo final. Estas entidades de control deben presentar sus informes al Congreso» 28 .

Hasta la terminación de este avance de investigación se han creado dos de estas instituciones:

1. La Unidad para la búsqueda de personas dadas por desaparecidas

Este componente del sistema integral de justicia previsto en el artículo 1 del Acto Legislativo fue creado mediante el Decreto-ley 589 del 5 de abril de 2017, en el cual se establece en el artículo 1 que «La UBPD es una entidad del Sector Justicia, de naturaleza especial, con personería jurídica, autonomía administrativa y financiera, patrimonio independiente y un régimen especial en materia de administración de personal».

La unidad se crea con suficiente autonomía e independencia pese a que su director es nombrado por el presidente del Comité de escogencia a que hace relación el acto legislativo que crea la JEP: «El director de la UBPD será escogido por el Comité de Escogencia establecido en el parágrafo del artículo transitorio 7 del Acto Legislativo 01 de 2017, sobre criterios formulados con base en las sugerencias del Comité Internacional de la Cruz Roja y de la Comisión Internacional sobre Personas Desaparecidas y será nombrado por el Presidente» ${ }^{29}$.

28 PARRA SALAS, Doris. Los acuerdos de paz: el futuro del Estado Colombiano. Gaceta Republicana. Universidad Republicana No. 20. Bogotá: febrero-marzo, 2017.

29 PRESIDENCIA DE LA REPUBLICA. Decreto 589 del 5 de abril de 2017, Artículo 16. Disponible en http:/ / es.presidencia.gov.co/normativa/normativa/DECRETO $\% 20589 \%$ 20 DEL\%2005\%20DE\%20ABRIL\%20DE\%202017.pdf. Consultada el 19 de mayo de 2017. 
2. La comisión para el esclarecimiento de la verdad, la convivencia y la no repetición

Este componente del sistema integral de justicia, previsto igualmente en el artículo 1 del Acto Legislativo, fue creado mediante el Decreto-ley 588 del 5 de abril de 2017, que en el artículo 1 establece que «De conformidad con el artículo transitorio 2 del Acto Legislativo 01 de 2017, póngase en marcha la Comisión para el Esclarecimiento de la Verdad, la Convivencia y la No Repetición (CEV), como un ente autónomo e independiente del orden nacional, de rango constitucional, con personería jurídica, con autonomía administrativa, presupuestal y técnica, sujeto a un régimen legal propio, por un período de tres (3) años de duración».

3. Unidad de lucha contra el paramilitarismo

Igualmente se pactó en el Acuerdo Final crear una Comisión Nacional de Garantías de Seguridad para el desmantelamiento de las organizaciones criminales responsables de homicidios y masacres o que atentan contra defensores de derechos humanos, movimientos sociales o movimientos políticos, incluyendo las organizaciones criminales que hayan sido denominadas como sucesoras del paramilitarismo y sus redes de apoyo, y la persecución de las conductas criminales que amenacen la implementación de los acuerdos y la construcción de la paz, como resultado de la persistencia del fenómeno paramilitar y con fundamento en las experiencias y recomendaciones elaboradas desde las víctimas ${ }^{30}$.

Se pactó otorgar a dicha unidad especial de lucha contra el paramilitarismo las siguientes competencias:

a. Perseguirá judicialmente las conductas y a las organizaciones objeto de su mandato.

b. Investigará las respectivas responsabilidades penales de los integrantes de estas organizaciones y remitirá la información obtenida sobre autores/as, instigadores/as, organizadores/as y financiadores/as de estas estructuras a la autoridad competente a efectos de apertura de juicio o de investigación por otro órgano que resultara competente.

c. Asumirá las investigaciones en los supuestos en los que se hayan producido compulsas de copias en la jurisdicción ordinaria o en la jurisdicción de Jus-

30 CONSEJERÍA DE PROYECTOS. et al. El desmantelamiento del paramilitarismo: aprendizaje y recomendaciones desde las víctimas. Bogotá: s.n., 2014. 
ticia y Paz para que se investigue la responsabilidad penal de aquellas personas que integraron redes de apoyo de organizaciones criminales incluidas en este acuerdo, incluyendo las organizaciones criminales que hayan sido denominadas como sucesoras del paramilitarismo.

d. Implementará planes metodológicos de investigación especializados respecto a los más graves hechos de victimización que las organizaciones y conductas objeto de este acuerdo ejecuten contra las mujeres, niñas, niños, adolescentes y población LGTBI.

e. Asumirá las investigaciones sobre los vínculos entre organizaciones criminales incluidas en su mandato, incluyendo las organizaciones criminales que hayan sido denominadas como sucesoras del paramilitarismo, y funcionarios/as del Estado.

f. De encontrar evidencia sobre la responsabilidad de funcionarios/as públicos, continuará conduciendo la investigación penal, y adicionalmente, dará traslado a la Procuraduría General de la Nación o a la Contraloría General de la República, con el fin de que se inicien las investigaciones disciplinarias y fiscales correspondientes.

g. De encontrar evidencia sobre la responsabilidad de funcionarios/as públicos, la Unidad solicitará ante las autoridades judiciales competentes la imposición de penas accesorias como la inhabilidad para el ejercicio de funciones públicas, entre otras.

h. Velará porque no existan normas que, directa o indirectamente, permitan o promuevan la existencia de estructuras paramilitares o sucesoras de estas, informando sobre lo anterior a la Comisión Nacional de Garantías de Seguridad para que se adopten las medidas pertinentes.

i. Podrá informar periódicamente a la opinión pública nacional e internacional acerca de los avances y obstáculos en el cumplimiento de su misión.

j. Coordinará con la Comisión para el Esclarecimiento de la Verdad, la Convivencia y la No Repetición y la Jurisdicción Especial para la Paz el intercambio de información sobre lo que sea de su competencia. ${ }^{31}$

31 Acuerdo Final para la terminación del conflicto y la construcción de una paz estable y duradera", FARC-EP, Teatro Colón, Bogotá, 24 de noviembre de 2016, p. 102-103. 


\section{CONCLUSIONES}

Luego de cuatro años de conversaciones sobre la terminación del conflicto armado, el Gobierno Nacional de Juan Manuel Santos y la organización guerrillera Fuerzas Armadas Revolucionarias de Colombia (FARC) lograron un acuerdo final que incluye además de grandes cambios en la titularidad de la propiedad agrícola, la sustitución de cultivos ilícitos, la reforma política y un capítulo sobre justicia transicional para los actores armados y partícipes en el conflicto.

Refrendado el Acuerdo por el Legislativo el 1 de diciembre de 2017, se aprobó y sancionó el 4 de abril el Acto Legislativo nro. 1 de 2017 que crea el Sistema Integral de verdad, justicia, reparación y No repetición (SIVJRNR), la Jurisdicción Especial de Paz, la Comisión para el Esclarecimiento de la verdad, la convivencia y la no repetición, y la Unidad para la búsqueda de las personas dadas por desaparecidas.

El sistema integral establece como principios el reconocimiento de las víctimas, de la verdad plena sobre lo ocurrido en el marco del conflicto, la responsabilidad de quienes participaron de manera directa e indirecta y se vieron involucrados en graves violaciones del Derecho Internacional Humanitario, y el principio de satisfacción de los derechos de las víctimas a la verdad, a la justicia, a la reparación y garantías de no repetición.

Se busca además con la comisión del esclarecimiento de la verdad reconstruir una memoria histórica, con la unidad de búsqueda de desaparecidos establecer la verdad sobre lo ocurrido con ellos, y una justicia con énfasis en medidas restaurativas más que retributivas.

Sin embargo, pese al énfasis en los derechos de las víctimas, han surgido desde las organizaciones de derechos humanos y de víctimas algunas inquietudes sobre las diferencias y responsabilidades de los diferentes actores y partícipes ante la JEP, ya que no se establece un tratamiento equitativo y simétrico para acceder a la JEP, ni tampoco sobre el compromiso de decir la verdad y reparar a las víctimas.

Establecer estas diferencias y falencias que afecten los derechos de las víctimas es uno de los propósitos de esta investigación, con lo cual se busca superarlos a través de las normas reglamentarias que aún faltan por aprobar y promulgar, como a través del control de inexequibilidad que le corresponde realizar en forma automática la Corte Constitucional, control en que pueden participar en las audiencias públicas las víctimas u organizaciones que representen sus derechos en ejercicio del control ciudadano. 


\section{REFERENCIAS}

Acuerdo final para la terminación del conflicto y la construcción de una paz estable y duradera. Introducción. En: MORENO ALFONSO, René. Itinerario del proceso de paz en Colombia. Bogotá: Ediciones Nueva Jurídica, 2016.

Acuerdo final para la terminación del conflicto y la construcción de una paz estable y duradera. Bogotá: Fuerzas Armadas Revolucionarias de Colombia, FARC-EP, Teatro Colón, Bogotá, 24 de noviembre de 2016.

BAILONE, Matías. El autor de escritorio y el ejecutor fungible: una modesta aproximación a la teoría de Claus Roxin. Disponible en: http:/ / www. terragnijurista. com.ar/doctrina/autoria_mediata.htm. Consultada el 4 de abril de 2017.

CONSEJERÍA DE PROYECTOS, et al. El desmantelamiento del paramilitarismo: aprendizaje y recomendaciones desde las víctimas. Bogotá: s. n., 2014.

COORDINACIÓN COLOMBIA-EUROPA-ESTADOS UNIDOS. Propuesta de organizaciones sociales y de Derechos Humanos sobre criterios que deben regir el mecanismo de selección y escogencia de los candidatos a hacer parte del sistema integral de Verdad, Justicia, Reparación y No Repetición. Bogotá: CCEEU. 2017.

DEJUSTICIA. Cinco puntos que preocupan sobre la Jurisdicción Especial para la Paz. En: El Espectador. Disponible: http:/ / colombia2020.elespectador.com/pais/ cinco-puntos-que-preocupan-sobre-la-jurisdiccion-especial-para-la-paz. Consultada el 19 de mayo de 2017.

FEIERSTEIN, Daniel. En Colombia hubo conflicto armado y genocidio. Disponible en: http:/ / www.elespectador.com/noticias/cultura/hasta-que-el-estado-no-aclare-sus-nexos-con-el-paramilitarismo-el-genocidio-en-colombia-va-continuar-articulo-692264. Consultado el 13 de mayo de 2017.

PARRA SALAS, Doris. Los acuerdos de paz: el futuro del Estado colombiano. Gaceta Republicana. Universidad Republicana nro. 20. Bogotá: febrero-marzo, 2017.

\section{Normas y jurisprudencia}

COLOMBIA. CONGRESO DE LA REPÚBLICA. Acto Legislativo nro. 1 del 2017, art. nro. 16. Disponible en: http:/ / es.presidencia.gov.co/normativa/normativa/ ACTO\%20LEGISLATIVO\%20N\%C2\%B0\%2001\%20DE\% 204\%20DE\%20ABRIL \%20DE\%202017.pdf. Consultada el 19 de mayo de 2017.

COLOMBIA. CONGRESO DE LA REPÚBLICA. Ley 1820 del 30 de diciembre de 2016. Disponible en: http:/ / es.presidencia.gov.co/normativa/normativa/LEY\% 
201820\%20DEL\%2030\%20DE\%20DICIEMBRE\%20DE\%202016.pdf. Consultada el 19 de mayo de 2017.

COLOMBIA. CORTE CONSTITUCIONAL. Comunicado nro. 28 del 17 de mayo de 2017. Disponible en: http://www.corteconstitucional.gov.co/comunicados/ No. $\% 2028 \% 20$ comunicado\%2017\%20de\%20mayo \%20de\%202017.pdf. Consultada el 19 de mayo de 2017.

COLOMBIA. CORTE CONSTITUCIONAL. http:/ / www.corteconstitucional.gov.co/ comunicados/No.\%2052\%20comunicado\% 2013\%20de $\% 20$ diciembre $\% 20$ de $\%$ 202016.pdf. Consultada el 19 de mayo de 2017.

COLOMBIA. PRESIDENCIA DE LA REPÚBLICA. Decreto 587 del 5 de abril de 2017. Disponible en: http:/ / es.presidencia.gov.co/normativa/normativa/DECRETO\%20587\% 20DEL\%2005\%20DE\%20ABRIL\%20DE\%202017.pdf. Consultado 19 de mayo de 2017.

COLOMBIA. PRESIDENCIA DE LA REPÚBLICA. Decreto 589 del 5 de abril de 2017, Artículo 16. Disponible en http:/ / es.presidencia.gov.co/normativa/normativa/ DECRETO\% 20589\% 20DEL \% 2005\% 20DE\%20ABRIL\% 20DE\% 202017.pdf. Consultada el 19 de mayo de 2017.

\section{Cibergrafía}

CARACOL NOTICIAS. Vía libre a la implementación: Congreso refrendó nuevo acuerdo de paz con FARC. Disponible en: http:/ / noticias.caracoltv.com/acuerdo-final/ camara-de-representantes-refrendo-acuerdo-de-paz-con-las-farc. Consultada el 19 de mayo de 2017.

COLOMBIA. PRESIDENCIA DE LA REPÚBLICA. JEP y Justicia Transicional son ejes que garantizan implementación de acuerdos: Ministro del Interior. Disponible en: http:/ / es.presidencia.gov.co/noticia/170314-JEP-y-Justicia-Transicional-sonejes-que-garantizan-implementacion-de-acuerdos-Ministro-del-Interior. Consultada el 19 de mayo de 2017.

EL ESPECTADOR. La Corte Suprema se pronuncia por primera vez en un caso que involucra a la JEP. Disponible en: http:/ / www.elespectador.com/noticias/judicial/la-corte-suprema-se-pronuncia-por-primera-vez-en-un-caso-que-involucra-lajep-articulo-691355.- Consultada el 19 de mayo de 2017.

EL TIEMPO. Senado aprobó conciliación de la Justicia Especial para la Paz. Disponible en: http:/ / www.eltiempo.com/politica/congreso/senado-aprobo-conciliacion-dela-justicia-especial-para-la-paz-70322. Consultada el 19 de mayo de 2017. 
EL TIEMPO. Víctimas de extorsión no tienen deuda con la justicia: Fiscal General. http:/ /www.eltiempo.com/politica/ proceso-de-paz/fiscalia-dice-que-victimas-deextorsion-no-estaran-en-justicia-transicional-45069. Consultada el 19 de mayo de 2017.

EUROPA PRESS. Uribe acusa al Gobierno de «entregar la Justicia y la Constitución» a las FARC. Consultada el 19 de mayo de 2017.

Plebiscito sobre los acuerdos de paz de Colombia de 2016. Disponible en: https:// es.wikipedia.org/wiki/Plebiscito_sobre_los_acuerdos_de_paz_de_Colombia_ de_2016. Consultada el 19 de mayo de 2017.

RCN RADIO. En libertad el general Jaime Humberto Uscátegui tras acogerse a la JEP. Disponible en: http://www.rcnradio.com/nacional/libertad-general-jaimehumberto-uscategui-tras-acogerse-la-jep/ Consultado el 13 de mayo de 2017.

REVISTA SEMANA. Congreso aprueba la Jurisdicción Especial de Paz. Disponible en: http://www.semana.com/nacion/articulo/jurisdiccion-especial-de-pazcamara-de-representantes-aprueba-la-jep/519963. Consultada el 19 de mayo de 2017. 